\title{
Research on the Impact of Environmental Regulation on Technological Innovation of Paper Industry Based on Gray Analysis Method
}

\author{
Donghong Shan ${ }^{1}$, Chunxia Shan ${ }^{2,3, *}$ \\ ${ }^{1}$ School of Computer, Pingdingshan University, Pingdingshan City, China \\ ${ }^{2}$ School of Business, Xi' an International Studies University, Xi'an, China \\ ${ }^{3}$ School of Economics and Finance, Xi' an Jiaotong University, Xi'an, China \\ Email address: \\ 4335@pdsu.edu.cn (Donghong Shan), shanchunxia@xisu.edu.cn(Chunxia Shan) \\ ${ }^{*}$ Corresponding author
}

\section{To cite this article:}

Donghong Shan, Chunxia Shan. Research on the Impact of Environmental Regulation on Technological Innovation of Paper Industry Based on Gray Analysis Method. Advances in Applied Sciences. Vol. 5, No. 3, 2020, pp. 75-81. doi: 10.11648/j.aas.20200503.14

Received: August 16, 2020; Accepted: August 28, 2020; Published: September 17, 2020

\begin{abstract}
In recent years, the continuous development of economy has also promoted the vigorous development of China's paper industry, but the disadvantages of paper industry such as large water consumption and serious pollution are more prominent. Therefore, the government has formulated a series of environmental regulation policies to restrict the heavy pollution in the production process of paper industry. Research on the impact of environmental regulation on the technological innovation of the paper industry in the new era is conducive to improve the quality policy of environmental supervision of China's paper industry, which has good theoretical value and practical significance. The data in this paper are from a series of indicators of the paper industry from 2009 to 2018. Among them, the indicators to measure the level of technological innovation and the indicators to calculate the intensity of environmental regulation are selected. The relationship between the two is empirically analyzed by grey correlation method and regression analysis. The empirical results show that environmental regulation has a positive impact on technological innovation of China's paper industry.
\end{abstract}

Keywords: Environmental Regulation, Paper Industry, Technological Innovation, Grey Correlation Method

\section{Introduction}

At present, sustainable development has become the main strategy of China's economic development. As one of the pollution intensive manufacturing industries, the environmental pollution caused by paper industry is the focus of people's attention. The future of paper industry will be affected by more and more diversified and strict government and market environmental regulations, especially the technological innovation of the industry. Therefore, if appropriate environmental regulation policies are put forward to adjust the social environment, the paper industry can be encouraged to actively carry out technological innovation, which will help to solve the problems of serious pollution and shortage of raw materials in China's paper industry, so as to gradually realize the sustainable development of the paper industry. This paper mainly studies the impact of environmental regulation on the technological innovation of the paper industry, which will be conducive to improve the quality management of environmental supervision of China's paper industry, and has good theoretical value and practical guiding significance.

\subsection{Research and Development History of Environmental Regulation and Technological Innovation}

\subsubsection{History of Foreign Research}

Foreign scholars have done a lot of research on the relationship between environmental regulation and technological innovation. There are two main viewpoints: one is that environmental regulation promotes technological innovation. The famous "Porter Hypothesis" put forward by Porter $[1,2]$ is a theoretical hypothesis about the impact of 
environmental regulation on technological innovation. He agreed that environmental regulation would increase the production cost of enterprises in a short period of time, thus affecting the efficiency and market competitiveness of enterprises, which was not conducive to enterprise innovation. However, "Porter Hypothesis" did not stop at static research, but focused on the impact of environmental regulation on enterprise technological innovation under the changing environment. Porter believes that after experiencing short-term cost, environmental protection laws and regulations will promote technological innovation, be conducive to the company's economic development and win market competitiveness. Lanjouw and Mody [3] used data from the $1970 \mathrm{~s}$ to study the relationship between environmental regulation and technological innovation. The cost of pollution control they used was used as an explanatory variable to measure the intensity of environmental regulation, and the number of patent applications was used as an explanatory variable to measure innovation ability. The final result shows that the intensity of environmental regulation is positively related to technological innovation. Jaffe and Palmer [4] used the data of American manufacturing industry from 1975 to 1991 to analyze the relationship between environmental regulation and technological innovation. They use pollution control costs as explanatory variables to measure the intensity of environmental regulation, and the number of research and development expenditures and patent applications to measure technological innovation. The results show that there is a positive correlation between $\mathrm{R} \& \mathrm{D}$ (research and development,) expenditure and pollution control cost after controlling the above-mentioned characteristic variables. Brunnermeier and Cohen [5] used data from 146 manufacturing enterprises in the United States from 1983 to 1992. They wanted to study the relationship between environmental regulation and industrial technological innovation. The results showed that there is a significant positive correlation between the number of patent applications and environmental regulation. Carmenle and Robert Innes [6] used corporate pollution emissions to explain the extent of environmental regulation. They used data from 127 U.S. manufacturing industries from 1989 to 2002 to examine the relationship between corporate emissions and environmental technology patents. The results show that there is a significant negative correlation between pollution emissions and environmental protection technology patents. The less pollution emissions, the stronger the government's environmental supervision, the stronger the environmental supervision, and the more environmental protection technology patents. It could be seen that environmental regulation can effectively stimulate technological innovation. Lanoie and Ambec [7] conducted a statistical analysis of data from many factories in the European Union, the results showed that environmental supervision could not only promote environmental innovation, but also reduce production costs under certain conditions. Lanoie, patry and lajeunesse [8] empirically analyzed the relationship between the strictness of environmental regulation and TFP growth, the empirical results are consistent with Porter's hypothesis. The impact of environmental regulation on productivity is negative in the same period and positive in the long run.

The second view of scholars on the relationship between environmental regulation and technological innovation is that environmental regulations hindered technological innovation. On the contrary, some scholars criticized Porter hypothesis. Many scholars believed that environmental regulation would lead to the increase of enterprise cost and the decline of competitiveness based on the "restriction hypothesis". "Restriction hypothesis" emphasizes that environmental regulation will have a negative impact on technological innovation of enterprises. Barber and McConnell [9] used the relevant data of the paper industry, chemical industry, stone industry and other seriously polluted industries in the United States for analysis. The research showed that environmental regulation had caused the rise of enterprise cost, but not the increase of enterprise output. It could be said that the impact of environmental regulation on technological innovation was negative. Branlund et al. [10] analyzed the data of Swedish paper industry, and found that strict environmental regulation could make the situation of regulated companies worse. Gray and shadbegian [11] used the data of the paper industry, refining industry and steel industry in the United States from 1979 to 1990 to study the relationship between environmental regulation and total factor productivity. The results showed that the relationship between environmental regulation and productivity is negative, and the cost increase caused by strict environmental regulation has not been effectively offset. Marcus Wagner [12] used German manufacturing data to construct an empirical analysis of the relationship between environmental management, environmental innovation and patent application. The results showed that the implementation level of environmental management system has a negative impact on innovation activities.

\subsubsection{Domestic Research}

Compared with the research of foreign scholars, domestic scholars' research on the impact of environmental regulation on technological innovation started late. Now, the focus of environmental regulation research is the impact of environmental regulation on industrial competitiveness, performance and technological innovation. Xiuqin Zhang et al. [13] studied the impact of environmental regulation on the export competitiveness of these industries based on the data provided by pollution intensive industries. The results showed that environmental control is "inverted $U$ " because of its export competitiveness. This showed that the improvement of environmental regulation improves competitiveness. Kai Wang [14] also conducted in-depth discussion on pollution intensive industries. The results showed that in the early stage, environmental regulation would inhibit the export competitiveness of Chinese industries, but with the improvement of environmental 
regulations, enterprises would also improve their technology, innovation level and the final growth of export trade. Xiuzhen Li et al. [15] also conducted a study on pollution intensive industries and concluded that the change of environmental tax has an indirect impact on industrial competitiveness. Tuochen $\mathrm{Li}$ et al. [16] studied the relationship between different environmental monitoring tools and high-tech industry performance. The results showed that market incentive environmental monitoring tools and voluntary environmental monitoring tools greatly promote industry performance, while command and control environmental monitoring tools have no significant impact on industry performance. Ke Jiang and Xianxiang Lu [17] conducted an empirical analysis on the impact of China's environmental regulations on three types of technological innovation capacity. Research showed that environmental regulation must cooperate with some human capital to promote technological innovation. Li Yang, Xinghua Dang et al. [18] conducted an empirical analysis of 37 industrial segments in China. The results showed that environmental regulation has a positive effect on technological innovation, and has a certain guiding significance, but for different industries, the promotion ability of environmental regulation is different. Shuangxi He [19] studied the impact of environmental regulation on technological innovation of paper industry based on the relevant data of China's paper industry from 2004 to 2012. The empirical results show that the impact of environmental regulation on technological innovation of China's paper industry is positive, and the impact has a certain lag. Yumei He and Qiao Luo et al. [20] conducted an empirical analysis based on the number of provincial panels in China from 2007 to 2014, the results show that: there is a significant positive correlation between environmental regulation and technological innovation, and environmental regulation can improve productivity through promoting technological innovation. This also draws the conclusion that whether the "strong Porter Hypothesis" is tenable depends on the intensity of environmental regulation, and the implementation of more stringent environmental regulation will help to improve the productivity and competitiveness of enterprises. Feng zheng Wang et al. [21] selected panel data of 30 provinces in China from 2000 to 2011, and concluded that: environmental regulation significantly affects enterprise technological innovation. Chunxia Shan et al. [22] used panel data of 28 industrial industries in China to study the impact of environmental regulation on technological innovation in industrial industries. The results show that, in the long run, environmental regulation has a significant positive impact on technological innovation of industrial industries. Xuan Chen et al. [23] studied the differences in the impact of environmental regulations on technological innovation of enterprises with provincial manufacturing scale and above as samples from 2010 to 2015. The results show that: the impact of environmental regulation on technological innovation is significantly positive.

\subsection{Analysis of Issue}

The above-mentioned domestic and foreign scholars have conducted extensive research on the impact of environmental regulation on technological innovation, but there are still some shortcomings: there are many indicators to measure the intensity of environmental regulation, but only one or several indicators are usually selected in the study, so the calculation data of environmental regulation intensity is weak, which may have a certain impact on the final results. In the future, when calculating the intensity of environmental regulation, it is possible to choose some indicators to quantify, and then the comprehensive analysis results may be more realistic.

Similarly, there are many indicators to measure the level of technological innovation, but in the research, only one indicator is usually used to measure the level of technological innovation, which may cause deviation to the results. At the same time, we can find that previous studies often regard all industries as the object of environmental regulation, thus producing more macro final recommendations. The subsequent research can be more targeted at industry or regional research, aiming to provide more effective reference for industries or enterprises.

\section{Research and Design Factors Analysis}

\subsection{Data Sources}

The data of this paper come from 2009-2018 annual report of China paper industry, China Science and technology statistical yearbook and Guotai'an database. As a number of reports and databases release data according to the national five-year plan, and now it is in the 13th five year plan, and the data after 2019 has not been released completely. Therefore, in order to ensure the effectiveness of the follow-up data analysis, the data from 2009 to 2018 are selected. Among them, the five three-waste-indicators involved in the calculation of environmental regulation intensity: wastewater discharge, chemical oxygen demand (COD) emissions, sulfur dioxide emissions, smoke and dust emissions, and solid waste production, the above mentioned are obtained from the annual report of China's paper industry and the statistical yearbook of China's science and technology.

Among the five indexes involved in the calculation of technological innovation level, the number of $\mathrm{R} \& \mathrm{D}$ personnel, the internal expenditure of $\mathrm{R} \& \mathrm{D}$ funds, the expenditure of new product development and the profit of new products come from Guotai'an database and network resources. The number of valid patent applications comes from the Guotai'an patent application database.

\subsection{Index Selection and Calculation}

\subsubsection{Selection of Technological Innovation Index}

There are many indicators to measure the level of technological innovation. Considering the availability of data, this paper selects two types of indicators: technological innovation investment indicators and technological innovation 
production indicators, and then carries out data analysis. The investment indicators include the number of R \& D personnel, internal $\mathrm{R} \& \mathrm{D}$ expenditure and new product development expenditure. The production index includes the number of valid patent applications and the profit of new products.

1. Number of R \& D personnel in paper industry

The number of $\mathrm{R} \& \mathrm{D}$ personnel is the number of research and development personnel. The full name of $\mathrm{R} \& \mathrm{D}$ is research and development, which refers to the systematic creative activities in the field of science and technology in order to increase the total amount of knowledge (including the total amount of human culture and social knowledge), and use these knowledge to create new applications, including basic research, applied research and experimental development. The number of R \& D personnel can measure the amount of R \& D resources invested in an industry in a certain period of time.

2. Internal expenditure of $\mathrm{R} \& \mathrm{D}$ funds

Internal $\mathrm{R} \& \mathrm{D}$ expenditure refers to the actual expenditure of $\mathrm{R} \& \mathrm{D}$ activities of enterprises and institutions. It includes direct expenditure of $\mathrm{R} \& \mathrm{D}$ project activities, management fee, service fee, related capital expenditure and outsourcing processing fee of indirect R \& $\mathrm{D}$ activities. Internal $\mathrm{R} \& \mathrm{D}$ expenditure can be used to measure the amount of $R \& D$ resources invested in a certain period of time.

3. New product development expenditure

The expenditure of new product development refers to the expenditure of research and development of new products in the internal expenditure of enterprise science and technology activities, including new product research, design, model development, testing, testing and other expenses. Compared with internal R \& D expenditure, it covers a wider range and can also be used to measure the amount of R \& D resources.

4. Number of valid patent applications

The number of valid invention patents refers to the number of authorized patents approved by the State Intellectual Property Office. Effective means that the patent has been approved and authorized by the State Intellectual Property Office; the annual fee should be paid in time for normal maintenance; and the patent has not exceeded the legal protection period. The number of valid patent applications can be used to measure the innovation level of enterprises more intuitively.

\section{New product profit}

Profit is equal to income minus expenditure. The annual profit of new products involved in this paper is the same as that of the annual profit of new products involved in this paper. We can get a better understanding of the market performance of new products produced under the technological innovation of enterprises and reflect the level of technological innovation of enterprises.

\subsubsection{Selection of Environmental Regulation Indicators}

The intensity of environmental regulation refers to the degree of environmental protection in a country or region. At present, most of the domestic literatures measure the intensity of environmental regulation by a single index, resulting in a single description of the intensity of environmental regulation. In this paper, through the selection of industrial three-waste- indicators to measure, in order to more comprehensively explain the intensity of environmental regulation, the selected indicators are wastewater discharge, chemical oxygen demand (COD) emission in wastewater, sulfur dioxide emission, smoke and dust emission, and solid waste production.

1. Standardize the five indexes of the selected industrial three-wastes, that is, divide the original value of the index by the average value $\beta_{\mathrm{j}}$ of each index $\mathrm{j}$. The formula is as follows:

$$
Y_{\mathrm{ij}}=X_{\mathrm{ij}} / \beta_{\mathrm{j}}
$$

Where $\mathrm{i}$ represents different years and $\mathrm{j}$ represents different pollutants $(j=1, \ldots \ldots, 5$, among them, "1" wastewater discharge, "2" COD emission, "3" sulfur dioxide emission, "4" smoke and dust emission, "5" solid waste production).

2. Calculate the adjustment coefficient of each index, so as to find the relationship between the data better. The formula is as follows:

$$
K_{\mathrm{ij}}=\frac{Q_{i}}{\sum Q_{i}} / \frac{E_{\mathrm{ij}}}{\sum E_{\mathrm{ij}}}
$$

Among them, $\mathrm{n} 1$ is the proportion of paper industry total output value Qi in the nationwide total industrial output value $\sum \mathrm{Qi}$, and $\mathrm{n} 2$ is the emission of pollutants produced by paper industry in different years Eij accounts for the nationwide total amount of similar pollutants $\sum \mathrm{Eij}$, and the ratio $\mathrm{Kij}$ is the proportion of $\mathrm{n} 1$ to $\mathrm{n} 2$.

3. According to the standardized value of each index and the adjustment coefficient of each index in different periods, the intensity of environmental regulation in the year is calculated, the formula is as follows:

$$
E R S_{i}=\sum_{j=1}^{5} K_{i j} Y_{i j}
$$

\section{Data analysis}

\subsection{Grey Relational Grade Method}

The grey correlation analysis method is one of the grey system analysis methods. Measure the degree of association between two systems, which changes with time or different objects, is called the degree of association. In the process of establishing the model, if the change trend of the two factors, that is, the degree of synchronous change is higher, it can be said that the degree of correlation between the two factors is high; otherwise, it indicates that the correlation degree of the two factors is low. Therefore, the grey correlation method is based on the similarity or dissimilarity between the development trends of factors, that is, the "grey correlation degree" as a method to measure the correlation degree between factors. The reason why we choose the grey 
correlation analysis method instead of the common regression analysis method is that regression analysis has high requirements for data and high requirements for data distribution. Grey relational analysis is suitable for the case of imprecise mathematical relationship between two factors of simple data. The data studied in this paper has limitations, and the use of grey correlation analysis can make up for one of the defects.

1. Using the mean value method to standardize the data of five technological innovation indicators;

2. Calculate the absolute difference after processing the original data:

$$
\Delta_{0 a}(t)=\left|x_{0}(t)-x_{a}(t)\right| t=1,2, \ldots, n
$$

In the formula, $x_{0}(\mathrm{t})$ is the reference column data (in this paper, the reference column data is the environmental regulation intensity), $x_{\mathrm{a}}(\mathrm{t})$ represents the data of the comparison column a $(\mathrm{a}=1 \ldots . .5, " 1 "$ is the number of $\mathrm{R} \& \mathrm{D}$ personnel, "2" internal R \& D expenditure, "3" expenditure on new product development, "4" number of valid patent applications, "5" profit of new products).

After calculation, the correlation coefficient is obtained. The minimum value of $\Delta \mathrm{oa}$ is set as $\Delta \mathrm{min}$, the maximum value is set as $\Delta \max$, and the correlation coefficient is $\varepsilon o a(t)$, the formula of $\varepsilon$ oa is as follows:

$$
\varepsilon_{o a}(t)=\frac{\Delta \min +\rho \Delta \max }{\Delta_{0 a}(t)+\rho \Delta \max }
$$

Among them, $\rho$ is the resolution coefficient, which is mainly to avoid the distortion of data calculation results caused by too large $\Delta \max$, and also help to make the difference of data more significant. The value range of $\rho$ is 0 $<\rho<1$, which is usually taken as $\rho \leq 0.5$, and $\rho=0.2$ in this paper.

4. The connection number is used to indicate the closeness between the reference sequence and the comparison sequence. However, because there is a lot of data in the text, it is not possible to compare them visually. Therefore, this paper selects the average method to simplify the coefficient, so that the correlation can be obtained through subsequent comparison. The calculation formula is as follows:

$$
\mu_{0 a}=\frac{1}{n} \sum_{i=1}^{n} \varepsilon_{0 a}(t)
$$

in the formula $\mu$ oa is used to measure the degree of correlation between the comparison sequence and the reference sequence. The calculation results are shown in Table 1:
Table 1. Calculation table of correlation degree.

\begin{tabular}{llllll}
\hline & $\boldsymbol{\mu}_{01}$ & $\boldsymbol{\mu}_{02}$ & $\boldsymbol{\mu}_{03}$ & $\boldsymbol{\mu}_{04}$ & $\boldsymbol{\mu}_{05}$ \\
\hline correlation degree & 0.65 & 0.67 & 0.61 & 0.46 & 0.69 \\
\hline
\end{tabular}

According to the calculation table of correlation degree, the correlation between environmental regulation intensity and new product profit $\left(\mu_{05}\right)$ is the strongest, followed by R \& D internal expenditure $\left(\mu_{02}\right)$, the number of R \& D personnel $\left(\mu_{01}\right)$ ranked the third, and the fourth related factor was expenditure on new product development $\left(\mu_{03}\right)$, and the number of valid patent applications $\left(\mu_{04}\right)$ ranked the fifth.

\subsection{Regression Analysis}

This paper uses the data from 2009 to 2018 to analyze the impact of environmental regulation intensity on technological innovation of paper industry. The result of grey correlation analysis is that the correlation between environmental regulation intensity and new product profit is the highest. Therefore, the paper industry new product profit is selected as the explanatory variable $\mathrm{y}$, and the environmental regulation intensity ERS is selected as the explanatory variable $\mathrm{X}$. The results of regression analysis are shown in Table 2:

Table 2. Model Summary.

\begin{tabular}{lllll}
\hline Model & R & R square & $\begin{array}{l}\text { Adjusted R } \\
\text { square }\end{array}$ & $\begin{array}{l}\text { Error of standard } \\
\text { estimation }\end{array}$ \\
\hline 1 & $0.835 \mathrm{a}$ & 0.696 & 0.658 & 256.87033 \\
\hline
\end{tabular}

a. Predictive variable: (constant), ERS;

Dependent variable: new product profit.

Among them, the goodness of fit $\mathrm{R}$ square is the decisive coefficient of regression analysis, which indicates the closeness of scatter points formed by independent variables and dependent variables with regression curve. The value is between 0 and 1 , the larger the value is, the better the regression is. Here $\mathrm{R}$ direction is 0.696 , indicating that the regression relationship between $\mathrm{X}$ and $\mathrm{Y}$ is good.

Table 3. Test results of the model.

\begin{tabular}{lllll}
\hline Model & Sum of squares & mean square & F & P \\
\hline Regression & 1210845.428 & 1210845.428 & 18.351 & $0.003 \mathrm{~b}$ \\
1 residual & 527858.922 & 65982.365 & & \\
total & 1738704.350 & & & \\
\hline
\end{tabular}

Dependent variable: new product profit.

b. Predictive variable (constant) ERS.

It can be seen from table 3 that the F statistic value of the regression model used is $18.351, \mathrm{P}$ value is 0.003 , so the

\begin{tabular}{|c|c|c|c|c|c|c|}
\hline \multirow{2}{*}{ Model } & & \multicolumn{2}{|c|}{ Non standard coefficient } & \multirow{2}{*}{$\begin{array}{l}\text { Standard Coefficient } \\
\text { Test Version } \\
\end{array}$} & \multirow{2}{*}{$\mathbf{t}$} & \multirow{2}{*}{ sig } \\
\hline & & B & Standard error & & & \\
\hline \multirow{2}{*}{1} & Constant & -801.517 & 366.839 & & -2.185 & 0.045 \\
\hline & ERS & 56.340 & 13.152 & 0.835 & 4.284 & 0.003 \\
\hline
\end{tabular}
regression model we used has statistical significance.

Table 4. Regression result coefficient.

a. Dependent variable: new product profit 
In Table 4, the regression coefficient sig value is equal to 0.003 , less than 0.05 , indicating that the coefficient of ERS is statistically significant. Therefore, the regression relationship between profit $\mathrm{y}$ of new products and environmental regulation intensity $\mathrm{x}$ can be obtained:

$$
y=-801.517+56.340 x
$$

\section{Conclusion and Suggestion}

\subsection{Conclusion}

This paper analyzes the relationship between environmental regulation and technological innovation by grey correlation analysis and regression analysis

1. The results of grey correlation analysis show that the environmental regulation intensity of China's paper industry has different degrees of correlation with the five indicators of technological innovation level of paper industry. Among them the environmental supervision and the profit of new products were the highest (0.69). The second high is the internal expenditure of R \& D funds, and the correlation between the third ranked $\mathrm{R} \& \mathrm{D}$ personnel is also very strong, which are 0.67 and 0.65 respectively.

2. Among the indicators indicating the technological innovation level of the paper industry, the correlation between the intensity of environmental regulation and the number of valid patent applications is the lowest, which is 0.46 . It is not difficult to understand that as the paper industry is a traditional industry, people's demand for it is relatively single, so its innovation types have certain limitations, resulting in a low correlation between environmental regulations and the number of valid patent applications. There are two ways that environmental regulation affects technological innovation of paper industry: government incentive type and market induced type. The two ways promote the technological innovation of enterprises in different degrees.

3. Through regression analysis, the final regression relationship is obtained. It can be seen that the coefficient explaining the intensity of environmental regulation is positive, indicating that environmental regulation has an impact on the technological innovation of paper industry, and it is a positive impact. Therefore, according to the empirical analysis, we can draw a conclusion: in the new era, environmental regulation promotes the technological innovation of paper industry.

\subsection{Suggestions}

Through the above theoretical analysis and empirical research, it can be concluded that environmental regulation promotes the technological innovation of paper industry. To promote the level of technological innovation through environmental regulation and to make up for the cost caused by improving the intensity of environmental regulation are the main issues to be considered in the future development of the industry, that is, how to enlarge the positive impact of environmental regulation on technological innovation is the main goal in the future.

\subsubsection{Government Level}

Through the empirical research results: environmental regulation promotes the technological innovation of papermaking industry to a certain extent, we can know that China's current environmental supervision has not reached the best state. Therefore, the government can continue to strengthen the intensity of environmental regulation by adjusting various policy tools and strengthening supervision and punishment.

\subsubsection{Industry Level}

According to the research of this paper, the paper industry is the object regulated by environmental regulation, which has a certain passivity. However, the paper industry can still find some problems from its own, such as poor executive power and negative treatment of environmental protection problems. The effective realization of the purpose of environmental protection is inseparable from the government to formulate reasonable policies and strengthen the supervision, but also inseparable from the industry's own active participation and serious cooperation, so the industry can be improved from two aspects: eliminating the backward technological process and stimulating the industry's own independent innovation.

Only when the paper industry is aware of its own problems, cooperate with the government, actively participate in the formulation and implementation of environmental regulation policies, and actively carry out technological innovation, can the paper industry truly transform itself into a resource-saving and environment-friendly green enterprise, and obtain stronger competitiveness in the market competition.

\section{Funding Support}

Scientific Research Program Funded by Shaanxi Provincial Science and Technology Department (Program No. 2019KRM001) and Shaanxi Provincial Science and Technology Department (Program No. 18JK0646).

\section{References}

[1] Porter, M. E. America, s Green Strategy [J]. Scientific American, 1991 (4): 168.

[2] Porter, M. E and C. vander Linde. Toward a New Conception of the Environmental Competitiveness Relationship [J]. Journal of Economic Perspectives, 1995, 9 (4): 97-118.

[3] Lanjouw J O, Mody A. Innovation and the international diffusion of environmentally responsive technology [J]. Research Policy, 1996, 25 (4): 549-571.

[4] Jaffe A B, Palmer J K Environmental Regulation and Innovation: A Panel Data Study [J]. Review of Economics and Statistics, 1997, 79 (4): 610-619. 
[5] Brunnermeier S B, Cohen M A Determinants of environmental innovation in US manufacturing industries [J]. Journal of Environmental Economics and Management, 2003, 45 (2): 278-293.

[6] Carmen, E., Carrión-Flores, Robert Innes. Environmental Innovation and Environmental Policy: An Empirical Test of Bi-Directional Effects [R]. Working paper, 2006.

[7] Lanoie P, Ambec S, Scott I. When and Why Does it Pay to be Green? [D]. Working Papers Grenoble Applied Economics Laboratory (GAEL), 2007.

[8] Lanoie P, Patry M, Lajeunesse R. Environmental regulation and productivity: testing the porter hypothesis [J]. Journal of Productivity Analysis, 2008, 30 (2): 121-128.

[9] Barbera, A. J., \& Mcconnell. V. D. The Impact of Environmental Regulations on Industry Productivity: Direct and Indirect Effects [J]. Journal of Environmental Economics and Management, 1990 (1): 50-65.

[10] Brannlund R., Y. Chung et al. Emissions Trading and Profitability: The Swedish Pulp and Paper Industry [R]. Re PEc Working Papers, 1995.

[11] Gray W, Shadbegian R. Pollution abatement expenditure and Plant-level Productivity: Production function approach [J]. Ecological Economics, 2005 (4): 196-208.

[12] Wagner M. On the relationship between environmental management, Environmental innovation and patenting: evidence from German manufacturing firms [J]. Research Policy, 2007 (36): 1587-1602.

[13] Xiuqin Zhang, Minxin Zhang. Empirical analysis on the impact of environmental regulation on export competitiveness of China's environmental sensitive industries [J]. International trade issues, 2012 (05): 128-135.

[14] Kai Wang. Impact of environmental regulation on export competitiveness of China's industrial industries: a case study of pollution intensive industries [J]. Price theory and practice, 2012 (01): 80-81.

[15] Xiuzhen Li, Haiyan Tang, Guojiao Zheng. Impact of environmental regulation on export competitiveness of pollution intensive industries: analysis of the impact of factor output elasticity coefficient [J]. International trade issues, 2014 (07): 72-81.

[16] Tuochen Li, Yingying Ding. Research on the influence of control mechanism on the relationship between environmental regulation and technological innovation of high-tech enterprises [J]. Journal of information, 2012 (08): 198-203.

[17] Ke Jiang, Xianxiang Lu. Environmental regulation and technological innovation: Based on the analysis of provincial panel data of China from 1997 to 2007.

[18] Yang Li, Xinghua Dang, Xianfeng Han, Wenfei song. Heterogeneous effects of environmental regulation on long-term and long-term technological innovation: a two-stage analysis based on the perspective of value chain [J]. Scientific research, 2014 (06): 937-949.

[19] Shuangxi He. Research on the impact of environmental regulation on technological innovation of China's paper industry [D]. Hunan University of science and technology, 2016.

[20] Yumei He, Qiao Luo. Environmental regulation, technological innovation and industrial total factor productivity: a reexamination of the "strong Porter Hypothesis" [J]. Soft science, 2018, 32 (04): 20-25.

[21] Fengzheng Wang, Tao Jiang, Xiaochuan Guo. Government quality, environmental regulation and enterprise green technology innovation $[\mathrm{J}]$. Scientific research management, 2018, 39 (01): 26-33.

[22] Chunxia Shan, Zhong Wei Zhou, Zizhen Geng, Mingxue Zhou. Research on the impact of environmental regulation and industry heterogeneity on technological innovation in industrial industries [J]. Economic issues, 2019 (12): 60-67.

[23] Xuan Chen, Weiwen Qian. The impact of environmental regulation and industry heterogeneity on technological innovation of manufacturing enterprises-Based on the comparison between coastal and inland areas of China [J]. Science and technology management research, 2019, 39 (01): 111-117. 